\title{
Behavioural and Cognitive Psychotherapy and the BABCP: 50 years and counting
}

Fifty years and 15,000 members later, what started as the British Association for Behavioural Psychotherapy (BABP) and later became the British Association for Behavioural and Cognitive Psychotherapies (BABCP) has an extraordinary history. There have been staggering achievements over this period and there is much to celebrate. The development of the Association has been helped along by some extraordinary people; sadly, the last year has seen the passing of two giants in our field, Jack Rachman and Tim (Aaron) Beck. These two were exemplars of what makes cognitive behaviour therapy (CBT) so amazing, and they contributed to the extraordinary blend of clinical art and clinical science which is at the heart of the best in both developing and implementing CBT. I had the privilege of seeing both of them working with patients, and can attest to the fact that both were first and foremost fine human beings who did their utmost to connect with and understand the experience and suffering of the people they sought to help. Much of their contribution to our field is built on their ability to do so, coupled with their generosity in communicating this to colleagues and students, and encouraging those around them to branch out and innovate.

Like most of us, Jack and Tim started from the position that the problems we see in mental health are understandable in terms of universal experiences affecting everyone, and that some people are affected both particularly severely and persistently in ways which mean that they become stuck in identifiable patterns of unhelpful responding. This type of understanding provides us as CBT therapists with the tools for empowering people experiencing mental health problems to deploy ways of developing more flexible responses, which in turn results in the ability to begin to overcome the problems they face. Jack Rachman and Tim Beck were giants in their field, and it is quite clear that all of us have benefited from the understanding and skills they communicated in our work with those who seek help from us. We are planning a special issue of Behavioural and Cognitive Psychotherapy to celebrate the work and contribution of Tim Beck to UK, European and worldwide cognitive and cognitive behavioural therapy. Another journal will be publishing a special issue celebrating Jack Rachman's enduring contribution.

Jack and Tim were, of course, not alone in helping our field develop in the way it has, and both would be the first to say that the behaviour therapy, which evolved into CBT, is necessarily a constantly changing field, driven by a combination of careful and empathic phenomenology (listening to those who come to use for help) with developing theory, empirical grounding and evidence. An important part of the 50th anniversary year will be reflections on the achievements and mis-steps we have made in this enterprise over this time, and what we can learn, which will allow us to go on confidently into the next 50 years. There are several ways we will be doing that. In this journal, there will be a bumper special issue later this year which will focus on current developments across a range of fields important to the Association and the Journal. It is also the 50th anniversary of the publication of this journal, which I have had the privilege of editing since volume 17, 1989. There will also be a twinned special issue, with a more specifically clinical focus, from our sister journal, the Cognitive Behaviour Therapist. We also understand that the annual conference (https://babcp2022.org/) is going to be particularly special this year, celebrating the achievements and potential of CBT 
across the wide range of areas where we contribute. There is also a history project looking at both the Association and the field with input both from Association members and historians.

In other news, I would remind you all that Behavioural and Cognitive Psychotherapy is a transformative journal, compliant with Plan S requirements, meaning that the journal is moving towards a full open access policy over the next few years. To help journals move towards sustainable Open Access, our publishers, Cambridge University Press, have partnered with over 1000 institutions to negotiate transformative agreements (also known as Read and Publish Agreements) which allows authors to publish their work as Gold Open Access at no cost to the authors or with a discount for the article processing charge (APC). You can find out more about these agreements and whether your institution is signed up to such an arrangement here: https://www.cambridge.org/core/services/open-access-policies/read-and-publish-agreements. Please note that eligibility is based on the corresponding author's affiliation. If you have any queries about this process, please do contact the journal office (journal.office@babcp.com).

All BABCP members have full online access to the journal through their BABCP membership. However, there is a long tradition of providing printed copies of the journal to all members, in addition to the online access everyone enjoys. The provision of tens of thousands of print copies, however, has consequences in terms of costs both to the BABCP and the planet. As you may have noticed, we now no longer automatically send print copies of the journal to members; only when they have opted in to receive them. This can be done here by logging into to your BABCP account: https://babcp.com/My-Account/Preferences. If you experience any problems with this, please contact the journal office as above and this can be arranged for you.

So, happy birthday year, BABCP, and may there be many more.

Paul Salkovskis, Editor, Behavioural and Cognitive Psychotherapy

Cite this article: Salkovskis P (2022). Behavioural and Cognitive Psychotherapy and the BABCP: 50 years and counting. Behavioural and Cognitive Psychotherapy 50, 129-130. https://doi.org/10.1017/S1352465822000054 